\title{
Can the Source Location of a Coloured Quartz Gemstone Be Determined from Non- Destructive Chemical Analysis?
}

Angela Halfpenny ${ }^{1}$.

1. Department of Geological Sciences, Central Washington University, Ellensburg, WA, USA.

Coloured varieties of quartz are extremely common and several are classed as semi-precious gemstones. For a long time varieties of quartz have been used to make jewellery, carvings and other household objects. With the advent of new non-destructive chemical analysis techniques is it possible to determine the growth location or source of a quartz gemstone? This project is interested in determining what trace element variations are shown within quartz gemstones of the same colour but from different source locations such as America verses Africa. Also, can the source region be narrowed down even more so that the same coloured quartz gemstones from one part of a country can be separated from ones which grew in another part of the country based on their respective trace element compositions?

Central Washington University (CWU) is located in Ellensburg, Washington State, where a blue quartz can be locally sourced and is known as the Ellensburg Blue. Ellensburg blues have be collected by locals for hundreds of years and the first account of the blue agate being used for jewellery is in 1905 [1] and Ellensburg residents continue to fossick for them today. In this paper we will be focusing upon using nondestructive, Bruker Tracer 5i, portable X-ray fluorescence spectrometer (pXRF) to measure the trace element signature of blue quartz samples [2]. In obsidian rock samples specific trace element concentration ratios have been identified to be distinctive of particular source locations. Archaeological samples, such as obsidian arrowheads, have been measured using pXRF and the trace element ratios have been used to determine the source location of the rock the arrowheads have been made from [3].

In this project $\mathrm{pXRF}$ analysis has been used to measure the trace element signature from blue quartz using samples where the provenance is known to create a blue quartz source trace element signature key. This key will be used to determine the source locations of samples with unknown origins. A secondary aim is to identify if the jewellery grade blue gemstones are distinct from other stones from the same area which are not of sufficient quality for jewellery use. To gather a large enough dataset of known and unknown origin blue gemstones for analysis, this project has involved working with multiple jewellery companies, the Kittitas Museum collection and the CWU geology department collection. Each stone was photographed and then analysed using the pXRF for major and trace elements using different operating conditions for the instrument. After measuring over a hundred and fifty blue quartz samples with known origins from Washington, Oregon, and Montana within the USA, from Turkey and Africa, the pXRF spectra showed that blue quartz samples from around the world show a similar trace element signature, but the concentrations of the trace elements varies between locations.

To further investigate the cause and controls of the blue colour a type example sample of blue quartz from each location and jewellery grade have been mounted up into $25 \mathrm{~mm}$ diameter resin mounts and polished for coincident data analysis via scanning electron microscope (SEM) imaging (BSE, CL), as well as, chemical (EDS) and crystallographic (EBSD) analysis [4]. A future aim of this study is to invite local residents along to the geology department at CWU to get their private quartz collections analysed to test the software's ability to source the samples origin location. 


\section{References}

[1] J.P. Thomson, "Ellensburg Blue" (Kittitas County Museum) p. 1-22

[2] R.H. Tykot, Applied Spectroscopy, 70(1) (2016) p. 42-56.

[3] A. B.M. De Francesco, G.M. Crisci, in "X-ray fluorescence spectrometry (XRF) in Geoarchaeology", ed. M.S. Shackley, (Springer) p. 81-108.

[4] A. Halfpenny et al, Microscopy and Microanalysis. 24(S1) (2018) p. 1100-1101


Figure 1 (A) Photo of a blue quartz gemstone collected from Ellensburg, WA, USA (field of view 16mm wide). (B) Reflected light image of sample from photo A. (C) Photo of a blue quartz gemstone with lace texture collected from Africa (field of view $14 \mathrm{~mm}$ wide). (D) Reflected light image of sample from photo C.

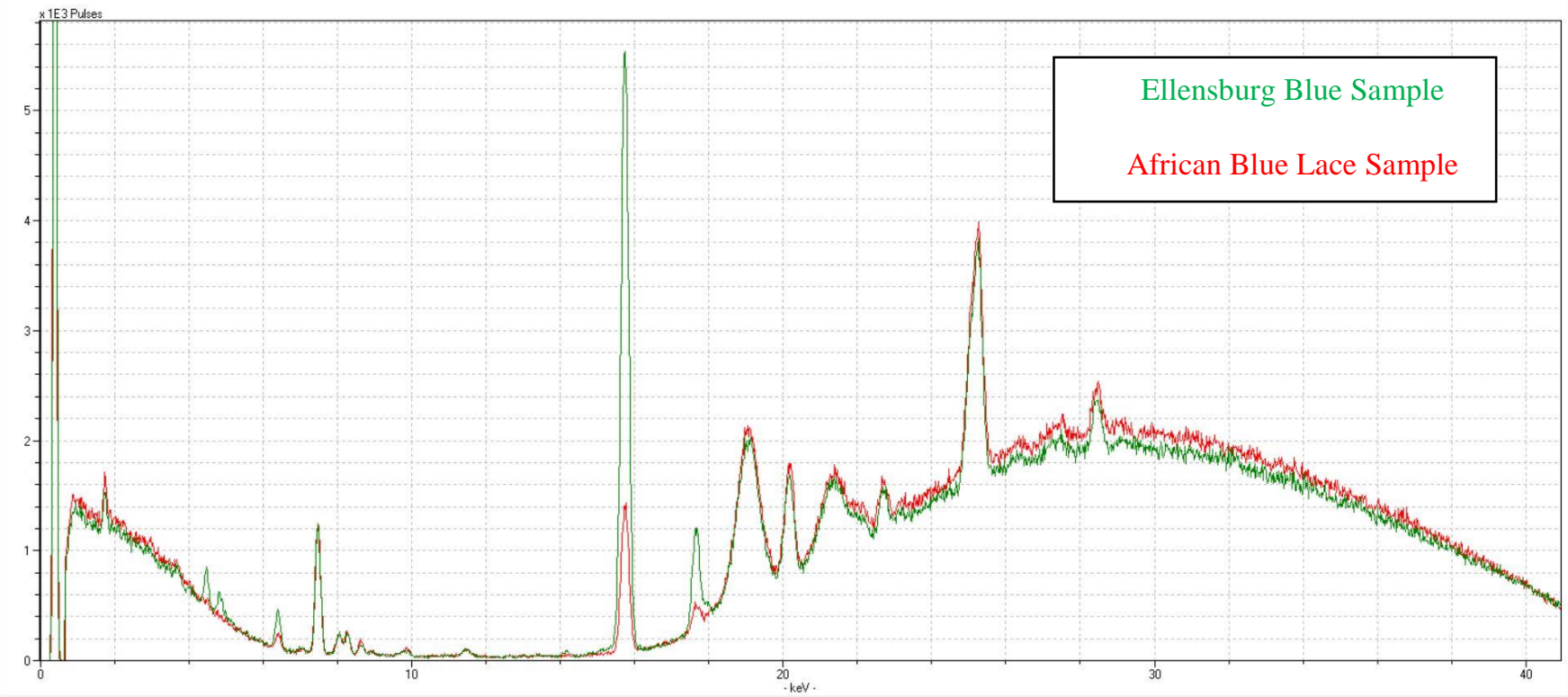

Figure 2 Collected x-ray fluorescence spectra for two different blue quartz samples. The spectra exhibit peaks at the same energies but the peak heights vary between the two spectra. Green line corresponds to the Ellensburg Blue sample and the red line to the African lace textured sample. 